\title{
VIVÊNCIAS NA NATUREZA E AS POSSIBILIDADES INVENTIVAS NA EDUCAÇÃO AMBIENTAL
}

\author{
Jane Márcia Mazzarino ${ }^{1}$ \\ Patrícia Angela Grisa de Assis ${ }^{2}$
}

\begin{abstract}
Resumo
Dentre as diversas correntes e perspectivas que compõem o que se pode denominar como o campo da educação ambiental, a perspectiva vivencial parte do pressuposto que, além dos conhecimentos transmitidos de forma tradicional, o contato direto com o ambiente natural proporciona atitudes de respeito e cuidado, desencadeando um processo de consciência ambiental. Denominada de Aprendizado Sequencial, a proposta de vivências na natureza, de Joseph Cornell, constitui-se de quatro fases que incluem diferentes jogos, por meio dos quais são trabalhados os cinco sentidos: despertar o entusiasmo, concentrar a atenção, dirigir a experiência e compartilhar a inspiração. $\mathrm{O}$ artigo discute as possibilidades inventivas na educação ambiental a partir das vivências sensíveis, tomando como base estudo empírico, os pressupostos norteadores dos documentos oficiais da educação ambiental e contribuições de teóricos da área.
\end{abstract}

Palavras-chave: Educação Ambiental. Vivências. Aprendizado Sequencial.

\section{EXPERIENCES IN NATURE AND THE INVENTIVE POSSIBILITIES IN ENVIRONMENTAL EDUCATION}

\begin{abstract}
Among the various currents and perspectives that make up what can be termed as the field of environmental education, experiential perspective assumes that, besides the knowledge imparted in traditional, direct contact with the natural environment provides attitudes of respect and care, triggering a process of environmental awareness. Named Flow Learning, the proposed sharing nature in Joseph Cornell consists of four phases that include different games, through which are worked five senses: Awaken Enthusiasm, Focus Attention, Experience Directly and Share Inspiration. The article discusses the inventive possibilities in environmental education from sensitive experiences, based on empirical study, the guiding assumptions of the official documents of environmental education and theoretical contributions of the area.
\end{abstract}

Keywords: Environmental Education. Sharing Nature. Flow Learning.

\footnotetext{
${ }^{1}$ Professora no Programa de Pós-Graduação em Ambiente e Desenvolvimento do Centro Universitário Univates (UNIVATES, RS).janemazzarino@gmail.com

${ }^{2}$ Professora e Coordenadora do Curso de Pedagogia da Faculdade Roraimense de Ensino Superior, FARES, RR e Inspetora do Meio Ambiente pela Prefeitura Municipal de Boa Vista (PMBV-RR).pgrisa@ hotmail.com
} 


\title{
EXPERIENCIAS EN LA NATURALEZA Y LAS POSIBILIDADES INVENTIVAS EN LA EDUCACIÓN AMBIENTAL
}

\begin{abstract}
Resumen
Entre los diversos aspectos y perspectivas que constituyen lo que puede denominarse como el campo de la educación ambiental, la perspectiva vivencial asume el presupuesto que, además de los conocimientos impartidos en la forma tradicional, el contacto directo con el entorno natural proporciona el respeto y actitudes de cuidado, desencadenándose un proceso de sensibilización ambiental. Llamado aprendizaje secuencial, las experiencias propuestas en la naturaleza, según Joseph Cornell, se compone de cuatro fases diferentes que incluyen juegos, a través de los cuales se puede desarrollar los cinco sentidos: despertar el entusiasmo, concentrar la atención, conducir la experiencia y compartir la inspiración. El artículo analiza las posibilidades inventivas de la educación ambiental desde las experiencias sensibles, tomando como base estudio empírico, los supuestos rectores de los documentos oficiales de la educación ambiental y los aportes teóricos de la zona.
\end{abstract}

Palabras-llave: Educación ambiental. Vivencias. Aprendizaje secuencial.

\section{Introdução}

O objetivo deste artigo é discutir as possibilidades inventivas na educação ambiental a partir das vivências sensíveis, tomando como base estudo empírico, os pressupostos norteadores dos documentos oficiais da educação ambiental e contribuições de teóricos da área.

A educação ambiental surge, na contemporaneidade, a partir dos movimentos ecológicos, que buscavam uma prática de conscientização capaz de chamar a atenção para a finitude e má distribuição no acesso aos recursos naturais. Em 1970, se intensificam os debates sobre a problemática ambiental do mundo. A Organização das Nações Unidas (ONU) promoveu, no ano de 1972, em Estocolmo, a Conferência Mundial sobre Meio Ambiente, evento histórico onde se discutiu a necessidade de serem desenvolvidos processos de educação ambiental para o enfrentamento dos problemas ambientais. Daí em diante, muitos outros encontros regionais, nacionais e internacionais discutirão a relação entre sociedade e ambiente, formulando-se propostas relacionadas à educação ambiental.

Na Conferência Mundial sobre Meio Ambiente de 1992, a Rio 92 ou Eco 92, firmouse a necessidade de se investir em educação ambiental. É quando surge o Plano de Ação Agenda 21, pelo qual se firmaram compromissos entre as cúpulas de diversos países.

A educação ambiental teve reconhecimento no cenário nacional brasileiro com a instituição da Política Nacional de Educação Ambiental (PNEA), Lei n 9795, aprovada em 1999 e regulamentada pelo Decreto $\mathrm{n}^{\circ} 4281$ de 2002, a partir da qual foram legalizados seus princípios, transformando-a em um componente de políticas públicas (BRASIL, 1999).

Os eventos geraram debates e a construção de documentos norteadores, que se refletem na relação entre sociedade e ambiente, engendrando a construção de valores e de sentidos. Tomando-se os pressupostos hegemônicos do campo da educação ambiental, entende-se que esta se volta para uma mudança de atitudes e hábitos do homem em relação ao meio no qual está inserido, que possibilite a construção de uma racionalidade ambiental, a qual implica a formação de um novo saber e a integração interdisciplinar do conhecimento (LEFF, 2001). 
Dentre as diversas correntes e perspectivas que compõem o que se pode denominar como o campo da educação ambiental, a perspectiva vivencial parte do pressuposto que, além dos conhecimentos transmitidos de forma tradicional, o contato direto com o ambiente natural proporciona atitudes de respeito e cuidado, desencadeando um processo de consciência ambiental.

[...] pensaremos, sentados em nossa sala de aula, da mesma forma como se estivéssemos com os pés mergulhados em uma cristalina água de corredeiras? O que poderá ser mais provocador na busca da essencialidade do conhecimento do que uma caminhada reflexiva à mercê dos quatro elementos? (PERALTA, 2002, p. 116).

O contato direto com a natureza é, para Peralta (2002), uma maneira de estimular a percepção e interpretação ambiental. Outra autora que reflete e empreende processos de educação ambiental por meio da interação e de vivências com a natureza é Mendonça (2007). Para ela, interagir com a natureza por meio de métodos exploratórios, com a participação criativa dos envolvidos, amplia e aprofunda o conhecimento, influenciando seu refletir e pensar.

Para Mendonça (2007), a escola tem trabalhado fortemente a transmissão dos conteúdos, baseada na possibilidade de conhecer sem vivenciar as informações e sem contextualizá-las, de modo que sejam transformadas em saberes. A educação ambiental vivencial estabelece que o aprendizado seja realizado através do corpo, da percepção, dos sentidos, considerando o indivíduo de forma integral.

A educação ambiental vivencial baseia-se no estímulo ao contato direto com a natureza, buscando a reintegração do ser humano ao meio natural, tendo como objetivo uma consciência crítica e transformadora. Esse contato deve ser planejado, objetivando despertar o reencantamento pelo ambiente, promovendo "comportamentos inovadores e criadores de novos modos de viver, de novas culturas (MENDONÇA, 2007, p. 120).

Pensar e vivenciar atividades com a natureza é uma proposta desenvolvida por Joseph Cornell, educador naturalista, que está sendo disseminada, no Brasil, pelo Instituto Romã, ao qual Mendonça está atrelada.

O termo vivências com a natureza foi definido para designar, em português, a expressão sharing nature. Cornell desenvolve, desde a década de 1970, atividades, jogos e exercícios que proporcionam uma aproximação e interação do indivíduo com o meio ambiente, propondo "processos de autoconhecimento, de abertura para a experimentação com os seres vivos e um profundo conhecimento e respeito pela natureza humana" (MENDONÇA, 2000).

Para Cornell (1997, p.13):

À medida que começamos a sentir uma comunhão com os seres vivos que nos rodeiam, nossas atitudes tornam-se mais harmoniosas e fluem com naturalidade, e, por conseguinte, passamos a nos preocupar com as necessidades e o bem-estar de todas as criaturas.

As atividades propostas pelo método de Cornell objetivam a ressignificação de sentimentos, desenvolvendo o respeito e admiração pela natureza. Assim, "cada brincadeira cria uma situação, ou uma experiência, na qual a natureza é a mestra" (CORNELL, 1996, p. 04).

O pressuposto norteador do método é que apenas as informações e conhecimentos são insuficientes para causar uma transformação na forma de os seres humanos se relacionarem com a natureza. É o equilíbrio entre o sentimento e a razão que proporcionaria o entendimento global da natureza (MENDONÇA, 2000). 
As experiências com a natureza referem-se a modos de perceber, sentir, compreender e vivenciar o universo, aposta Cornell, para quem o principal ingrediente para uma efetiva conservação dos espaços naturais é a afetividade. A aposta no afeto e nas emoções, como parte fundamental do processo de educação, é um paradigma emergente, que se articula com o pensamento de Maturana (1998), Barcelos (2003), Duarte (2004), Silveira (2009), Mazzarino e Vier (2013), entre outros.

\section{Vivências na natureza: o método}

Para propor momentos de exploração com a natureza, proporcionando aos grupos ocasiões alegres e gratificantes, Cornell (1996) criou cinco regras de ensinamento ao ar livre. A primeira regra apresentada por Cornell se traduz em ensinar menos e compartilhar mais sentimentos e pensamentos, explorando-se, respeitosamente, as emoções desencadeadas pelo processo educativo, criando, assim, uma relação de confiança e companheirismo. Perceber a importância da receptividade é outra regra. Significa ouvir e estar atento, pois as atividades ao ar livre provocam um entusiasmo espontâneo, que também é um elemento de aprendizado. A concentração e a atenção, terceiro elemento, levam a sentir a importância das descobertas que surgirem. Observar, sentir e falar são três ações que correspondem à quarta regra sugerida por Cornell. Já a última é a alegria, que deve prevalecer durante o desenvolvimento das atividades, transformando-se, assim, na sua arma mais poderosa (CORNELL, 1996).

Para que os jogos e brincadeiras sejam mais produtivos, independentemente da idade e estado de espírito dos participantes, é necessário organizar uma sequência, que foi denominada por Cornell de Aprendizado Sequencial, e constitui-se de quatro fases que incluem diferentes jogos, por meio dos quais são trabalhados os cinco sentidos: a primeira visa despertar o entusiasmo; a segunda concentrar a atenção; a terceira dirige a experiência; enquanto na quarta fase se compartilha a inspiração (CORNELL, 2008).

Despertar o Entusiasmo é uma fase que se propõe ser divertida. Brincadeiras e atividades geram alegria e um fluxo de energia, criando uma atmosfera de entusiasmo e vivacidade para a construção de experiências de aprendizagem sutis e significantes. Após a diversão, quando os envolvidos estão se sentindo relaxados, entusiasmados e entrosados, a fase da Atenção Concentrada tem início. Seu objetivo é estimular a observação e harmonizar coração e mente com a natureza, por meio do estímulo dos sentidos. É o momento no qual estabelecem-se emoções tranquilas, que propiciam a Condução da experiência, etapa marcada pelas descobertas pessoais, o que, segundo Cornell, favorece o comprometimento com ideais ecológicos. É o momento, então, de Compartilhar a Inspiração, quando as pessoas relatam as experiências que tiveram no decorrer das atividades. Compartilhar reforça o sentimento de encantamento e faz com os participantes criem vínculos entre si.

O aprendizado sequencial tem por objetivo proporcionar uma experiência genuinamente positiva com a natureza. Depois de uma sessão conduzida com sucesso, cada participante adquire uma nova, agradável e sutil conscientização de sua unidade com a natureza e uma intensa empatia com a vida (CORNELL ,1997, p.17-18).

O método de Cornell é experimentado sutilmente por cada um, quando percebe que o simples ato de caminhar pelos espaços naturais proporciona momentos introspectivos e de tranquilidade. $\mathrm{O}$ que o autor faz é organizar a interação com a natureza em uma sequência gradativa de entusiasmo, atenção e introspecção, experiência e compartilhamento das emoções e afetos que emergem do contato consigo, com o outro e com o meio.

Assis (2014) investigou os sentidos emergentes em processos de educação ambiental 
baseados na aplicação do método de vivências no meio natural, entre alunos do Ensino Fundamental. Trata-se de um estudo pioneiro. O método, obviamente qualitativo, baseou-se nas pesquisas bibliográfica e de campo. O estudo foi realizado com alunos da Escola Estadual Barão de Parima, de Boa Vista, Roraima, região Norte do Brasil.

$\mathrm{Na}$ tentativa de estimular a percepção das crianças a partir da proposta vivencial foram desenvolvidas atividades lúdicas, relacionando-as aos conteúdos curriculares: MorcegoMariposa, Coruja e Corvos, Encadeamento, Passeio da Lagarta, Arca de Noé, Tons de Verde, Que Animal Sou Eu, Predador e Presa, Silhueta das Árvores, Construir uma Árvore e Animal Misterioso (CORNELL, 1996; CORNELL, 2008).

Nas vivências na natureza emergiram emoções e sentidos diversos, conforme o grupo evoluía nos encontros e conforme as atividades propostas: agitação, dificuldade de concentração e também concentração, entusiasmo, cooperação, interesse, ansiedade, competitividade, participação, atenção, desassossego, medo, preocupação, responsabilização, informação, inter-relação, vínculos, envolvimento, receptividade, isolamento, insegurança, riso, dificuldade, timidez, solidariedade, sensibilidade, cuidado, reflexividade, tranquilidade, desenvolvimento de habilidades, ampliação da percepção, sentir-se parte, diversão, dinamicidade, descontração, curiosidade, afetividade, intensidades, empolgação, percepção da vulnerabilidade da vida, criatividade, euforia, socialização, indecisão e encontro consigo, com seu corpo, com o outro e com o ambiente natural. Os alunos expressaram e relataram essa diversidade de afetos, além de afirmarem que as atividades despertaram sentimentos específicos em relação aos colegas quando participaram das vivências: companheirismo, união, respeito, alegria, educação, amizade, alegria e satisfação.

Uma análise de conteúdo dos pressupostos teóricos e estudos empíricos do campo da educação colocam essas mesmas palavras, que emergiram da observação analítica das vivências, como características de algo que ainda desafia as práticas escolares. Portanto, a pesquisa evidenciou que o método das vivências no âmbito da educação contribui na resolução do que, hoje, se constitui um problema do campo: a falta de entusiasmo e envolvimento dos atores envolvidos no processo educativo.

Obviamente, o estudo tratou da temática ambiental, mas outros temas podem ser abordados, tendo o ambiente natural, ao ar livre, como contexto físico e operacional de aprendizagem. Cornell (1997) afirma que o desenvolvimento de sentimentos de afetividade e de preocupação para consigo, com os outros e para com a natureza é a base para a construção de um processo educativo.

Ao realizar-se o cruzamento dos resultados obtidos por meio dos questionários e entrevistas com os sentidos que emergiram nas atividades desenvolvidas em cinco encontros com os alunos, observou-se uma mudança de atitude assumida por eles, percebida não só pela pesquisadora, mas também pela professora regente da sala, a qual afirmou que os alunos mostraram-se mais envolvidos e participativos em aula, (re) afirmando responsabilidades e compromissos relacionados à questão ambiental. Essa observação vai ao encontro do pressuposto de Cornell, de que o método das vivências favorece o comprometimento. Portanto, gera-se uma interface interessante entre um processo eminentemente estético, vivencial e afetivo com um posicionamento responsável em relação ao mundo que se experimenta.

A educação ambiental que objetiva o desenvolvimento de habilidades, a fim de transformar as atitudes do ser humano em relação ao meio utilizando-se dos métodos tradicionais, que, hegemonicamente, vem sendo utilizados pela escola, dificilmente tem conseguido atingir resultados que potencializem seres sensíveis. É mais comum obterem-se 
relatos conscientes acerca da problemática ambiental em relação a plantas, animais, água, resíduos e mudanças climáticas, temas também hegemônicos nas escolas.

De modo diferente, o aprendizado sequencial por meio das vivências estabelece-se como um retorno do ser humano ao contato primordial com a natureza, e, ao mesmo tempo, como uma tendência contemporânea cujo fim é uma aprendizagem autêntica.

No aprendizado vivencial, é o corpo inteiro que aprende, não só o cérebro, e ele aprende por que interage com o que deve ser aprendido. As vivências permitem que a pessoa se aproxime de si mesma, fazendo com que o aprendizado se torne autêntico, pois é seu próprio corpo que vai produzir o conhecimento (MENDONÇA, 2007, p.10).

A aprendizagem autêntica, para Mendonça (2007), caracteriza-se pela participação integral do sujeito na construção do conhecimento, e não pela transmissão dos conteúdos. No formato tradicional, explora-se a possibilidade de conhecer sem vivenciar, ou seja, sem se envolver com o conhecimento. Conceitos, proposições e comparações não despertam nos alunos novas percepções e novos sentimentos, afirma a autora. Contudo

Se a vivência for positiva, bem elaborada e conduzida, pode deixar no indivíduo a convicção, percebida corporalmente, de que a construção de novas relações com o mundo é possível e, de que as raízes dessa construção, encontram-se nele mesmo, na memória corporal da experiência que teve, adquirindo assim, uma maior autonomia para pensar sobre si mesmo e seu estar no mundo, empoderando-se para observar suas limitações e os pressupostos que subsidiam suas ações (MENDONÇA, 2007, p.121).

Nesse sentido, observou-se, por meio das atividades sequenciais realizadas entre os alunos de Boa Vista, que eles depararam-se com aspectos sutis, comprovando que a proposta sequencial baseada em vivências é um método despertador de novos sentidos e sensibilidades. As interações que se estabeleceram nas atividades vivenciais permitiram abordar o sujeito a partir do que Mazzarino e Vier (2013) consideram sua imediata presença com o meio ambiente, mediada pela emoção e pelo sentimento.

\section{Possibilidades inventivas na educação ambiental}

Essas possibilidades inventivas, que surgem em processos de educação ambiental, estão presentes em linhas e entrelinhas dos documentos oficiais, apesar de serem sempre mais repetidos e ressaltados os aspectos políticos, sintetizados em palavras como conflito, apropriação, democracia, participação, dialogia, consciência crítica, resolução de problemas, ação para mudanças sociais, econômicas, culturais e políticas, responsabilização, integração entre organizações, intervenção, agir na história, compromisso social, continuidade, articulação entre cidadania e justiça, sociedade e sustentabilidade, articulação entre cidadania, democracia e participação, formação de cidadãos conscientes, direitos e deveres do educando, meio ambiente como bem público, conquistar a cidadania, desenvolvimento de habilidades e competências por meio de práticas e projetos que enfoquem necessidades/problemas/interesses, empoderamento, protagonismo, uso de diagnósticos e indicadores em planejamentos estratégicos, institucionalização da educação ambiental, ações intersetoriais, formação, capacitação, parcerias, banco de dados, uso de mídia e tecnologias como instrumentos.

Após análise dos documentos que norteiam a educação ambiental no Brasil, identificamos essa forte vertente política, mas, também, nuances poéticas, expressas em palavras como vivenciar, energia, afetividade, subjetividade, imaginário, vínculo, 
sensibilidade, emoção, arte, sensações, corpo, vontade de ser, expressar, compartilhar, vida, escuta poética, acaso, temporalidades humanas não lineares, derivas, ecologias menores, fragilidade, intuição, arriscar-se, mover-se sem mapa, escuta dos desejos, vontades, silêncios, conversação, viver solidário e amoroso, mergulho na natureza, contato direto, sem escudos, abrir-se à percepção, exercitar a fala, buscar o incerto e o curioso, reencontro com a dimensão sensível, afloramento de dimensões adormecidas, reconhecimento do lugar habitado, realocação do ser humano no mundo, ressignificar relações, passar do discurso para a experiência sensível, reavivamento dos sentidos, redescoberta do potencial criativo.

Dos quatro documentos analisados (Tratado de Educação Ambiental para Sociedades Sustentáveis e Responsabilidade Global, Política Nacional de Educação Ambiental - PNEA, Programa Nacional de Educação Ambiental - ProNEA e Parâmetros Curriculares Nacionais PCNs) é nos PCNs (BRASIL, 1997) que encontramos uma perspectiva cuja ênfase é mais político-poética que eminentemente política. Os elementos de valorização do enfoque poético encontram-se em diversas passagens do documento que remetem à necessidade de sentir a natureza, reencantando-se por meio de vivências. Segundo o documento, os novos paradigmas que devem permear a educação ambiental apontam para uma forma de conhecimento que inclui energias e afetividade, influenciado por conceitos filosóficos e do holismo. "Só quando se inclui também a sensibilidade, a emoção, sentimentos e energias se obtêm mudanças significativas de comportamento. É preciso então lidar com algo que nem sempre é fácil na escola: o prazer" (BRASIL, 1997, p.182). É preciso desenvolver sensações, autoconhecimento corporal, formas de expressão das sensibilidades; sentir-se afetivamente ligado à natureza, já que os vínculos afetivos mobilizam a sentir-se parte, expressa o documento.

Essa perspectiva vivencial, sensível e estética é valorizada, também, por autores como Barcelos e Silva (2007, p. 141-142), quando reconhecem a importância da "escuta poética" e de "ousar agregar aos valores tradicionais do pensar, territorialidades humanas não lineares subjetividades, processos contraditórios e fragmentados, fraturados, os vetores poiéticos, a fragilidade e a não complementaridade".

Em outro texto, Barcelos (2003, p. 31) reafirma: "Há um desafio a enfrentar na educação e na educação ambiental: poetizar a educação assim como educar nossa palavra para a poesia". Poetizar a educação, para Barcelos, é exercitar a conversação proposta por Maturana, enquanto uma maneira de os humanos viverem juntos, de modo solidário e amoroso, em um linguajar comum. $\mathrm{O}$ que requer que o processo educativo leve em conta a "escuta dos desejos, vontades, silêncios, enfim, do diálogo com o imaginário" (BARCELOS; SCHLICHTING, 2008, p. 105).

Igualmente, Barcelos propõe a valorização dos fragmentos subjetivos em movimento, do afeto e de uma educação que procure por

[...] um ser incompleto, incerto, inacabado, criativo, curioso, e por tudo isso um sonhador de coisas a serem buscadas. Uma educação com tal preocupação dê, talvez, pistas que nos ajudem a entender o porquê de nos sentirmos perdidos entre as coisas e as pessoas. Seria uma educação não para as coisas e as pessoas. Seria uma educação não para a certeza. Não para a verdade. Mas sim para oxigenar aquilo que Paz chama de 'pensamentos circulares', que não nos deixam perceber o que está a emergir, e para o que ainda não temos nome. Um algo que brota aqui e agora. Porém um algo sem nome (BARCELOS, 2003, p. 43).

Catunda (2003) critica a criação de uma defesa perceptiva, que provoca o fechamento para o mundo e oprime a sensibilidade e as sociabilidades. No mesmo caminho, Silveira (2009) propõe a educação estética ambiental a fim de provocar o reencontro do humano com as dimensões sensível, fluida e poética, assim como com o mundo que o cerca, com o lugar 
habitado e com suas vivências. Uma educação que valorize as vivências, o erótico, a relação com o lugar, a religação, a liberdade, a subjetividade, os compartilhamentos, o pertencimento histórico-cultural, o afeto, a criatividade, a imaginação, permitindo afloramentos de dimensões adormecidas e o desenvolvimento humano integral. Nesse processo de encontro com o mundo, o autor, baseado na obra de Merleau-Ponty, afirma que o corpo é o elemento essencial. A carne é onde a experiência se materializa. A principal proposta do autor está sintetizada no fragmento que segue:

Ao educar a sensibilidade, a partir dessa relação afetiva entre ser humano e ambiente, também a relação do ser humano com seu igual é ressignificada, desenhando um novo sentido do agir ético. Avançar da dimensão essencialmente discursiva presente na educação ambiental para a dimensão vivencial: eis o aporte da educação estética ambiental (SILVEIRA, 2009, p. 380).

O autor questiona a predominância de uma educação ambiental de caráter críticoemancipatório, por considerar que não fornece, sozinha, possibilidades de mudanças efetivas, já que tende a se manter na esfera da discursividade. Ressalta, ainda, que "a educação estética ambiental não suprime a necessidade de um posicionamento crítico e contestatório em relação às problemáticas em questão", mas salienta a necessidade conjunta da "redescoberta do potencial criativo" e do "reavivamento dos sentidos" (SILVEIRA, 2009, p. 390). A necessidade de uma educação que amplie sua atuação para os domínios corporais e sensíveis é também proposta por Duarte, que defende

[...] uma vida mais plena, prazerosa e sabedora de suas capacidades e deveres face à consciência de nossa ligação com os outros e as demais espécies do planeta. Este talvez consista hoje no objetivo mais básico e elementar de todo e qualquer processo educacional, por mais especializado que ele possa parecer (DUARTE, 2004, p.181).

A educação deve convidar à apropriação, à exploração e à coexistência com a natureza, sem pretender dominá-la ou negá-la, mas entregando-se a um viver matriztico, afirma Maturana. Uma educação baseada no respeito e na colaboração, na criação de um mundo que admita o erro, que permita viver a responsabilidade pelas consequências de nossas ações, refletir sobre o que nos acontece, percebendo sua interdependência com a realidade. É preciso dar-se conta que "[...] nossa corporalidade nos constitui, e que o corpo não nos limita, mas ao contrário, nos possibilita" (MATURANA, 1998, p.53).

$\mathrm{O}$ autor reclama a valorização das emoções entrelaçadas no cotidiano como constituintes do viver humano e de todo sistema racional: "[...] emoções são disposições corporais dinâmicas que definem os diferentes domínios de ação em que nos movemos" (MATURANA, 1998, p.15). O caos não se instala com a inserção da emoção no sistema racional, mas quando perdemos nossa referência emocional, encontrando-nos, recorrentemente, em emoções contraditórias, diz o autor.

\section{Novas derivas}

Compreender os sentimentos, a partir das interações sensíveis que se estabelecem com o meio ambiente através de atividades vivenciais, é abordar o sujeito presente com a natureza. É demonstrar afeto, alegria e entusiasmo, um sentimento de acolhimento pelo meio ambiente.

As atividades vivenciais em ambientes naturais estimulam e propiciam o desenvolvimento da afetividade, o estabelecimento de vínculos do indivíduo consigo mesmo, com os outros e com o ambiente, a construção de novos valores, como responsabilidade e compromisso, o contato com saberes ambientais diversos e o despertar de sentidos que, muitas vezes, são ofuscados pelo intelecto. Ações de educação ambiental são capazes de 
transformar e desenvolver a consciência crítica de cada um quanto ao seu papel na sociedade, assim como desenvolver sua sensibilidade. É nesse sentido que as vivências apontam.

Propor possibilidades inventivas para a educação ambiental a partir da interação corporal com a natureza é uma proposta guiada pelo prazer e pela emoção de quem não quer falar sobre o prazer de mergulhar os pés em águas cristalinas, mas quer experimentar com o outro esse mergulho, assim como caminhadas silenciosas, brincadeiras com olhos vendados, construir mapas dos sons, explorar os espaços naturais, encontrar-se consigo, estar com o outro, ampliar a percepção dos sentidos, sentir o sol, a umidade, o cheiro da terra, comer fruta do pé, atentar para os sons, estar no mundo encarnando emoções sutis, brisa na pele dos braços e no pescoço, sentir-se aflorar na máxima potencialidade do que se é, fazendo jus a todos aspectos criativos que fluem em nós, deixar-se tomar por sentimentos singelos, ressignificar-se por meio de experiências genuínas, escancarar-se ao ar livre, sentir alegria, vivacidade e relaxamento. Enfim, trata-se tão somente de re-experimentar o mais velho modo de viver. É nisso que consistem as novas derivas que as vivências propõem para a educação ambiental.

\section{Referências}

ASSIS, P. de. Ressignificação de representações ambientais por meio de vivências na natureza: estudo de caso em uma escola de ensino fundamental. 2014, 162p. Dissertação (Mestrado em Ambiente e Desenvolvimento) - Centro Universitário Univates/Programa de Pós Graduação Ambiente e Desenvolvimento (PPGAD), Lajeado, 2014.

BARCELOS, V. Educação ambiental e literatura: a contribuição das ideias de Octávio Paz. In: NOAL, F. O. BARCELOS, V. H. de L. (Orgs.). Educação ambiental e cidadania: cenários brasileiros. Santa Cruz do Sul: Edunisc, 2003. p.23-56.

BARCELOS, V.; SILVA, I. S. da. Saberes, sabores e devorações - para uma educação ambiental antropofágica e pós-moderna. In: PREVE, A.M.; CORRÊA, G. (Orgs.) Ambientes da ecologia: perspectivas em política e educação. Santa Maria: Editora UFSM, 2007. p.139-166.

BARCELOS, V. SCHLICHTING, H. A. O amor como fundamento da aprendizagem humana em Humberto Maturana - uma contribuição à educação ambiental. In: BAGGIO, A. (Org.). Educação ambiental e complexidade: entre pensamentos e ações. Santa Cruz do Sul. Edunisc, 2008. p.99-120.

BRASIL. Política Nacional de Educação Ambiental. Lei $n^{\circ}$ 9.795, de 27 de abril de 1999. Dispõe sobre a educação ambiental, institui a Política Nacional de Educação Ambiental e dá outras providências. Brasília: Casa Civil, 1999. Disponível em: http://www.planalto.gov.br/ccivil_03/Leis/L9795.htm. Acesso em: 14 jun. 2010.

BRASIL. Secretaria de Educação Fundamental. Parâmetros Curriculares Nacionais: Meio Ambiente/Saúde. Brasília: MEC, $1997 . \quad$ Disponível em: http://portal.mec.gov.br/seb/arquivos/pdf/livro091.pdf. Acesso em: 01 dez. 2013.

CATUNDA, M. Educar e cultivar ambientes. In: NOAL, F. O.; BARCELOS, V. H. de L. (Orgs.). Educação ambiental e cidadania: cenários brasileiros. Santa Cruz do Sul: Edunisc, 2003. p.231-252.

CORNELL, J. Brincar e aprender com a natureza: guia de atividades infantis para pais e monitores. São Paulo: Melhoramentos, 1996. 
CORNELL, J. A alegria de aprender com a Natureza. São Paulo: Melhoramentos, 1997.

CORNELL, J. Vivências com a Natureza 2. São Paulo: Aquariana, 2008.

DUARTE JR, J. F. O sentido dos sentidos: a educação (do) sensível. Curitiba: Criar Edições, 2004.

INSTITUTO ROMÃ. Quem somos. Disponível em: < http://www.institutoroma.com.br/>. Acesso em: 10 fev. 2014.

LEFF, E. Saber Ambiental: Sustentabilidade, Racionalidade, Complexidade, Poder. Petrópolis: Vozes, 2001.

MATURANA, Humberto R. Emoções e linguagem na educação e na política. Editora UFMG: Belo Horizonte, 1998.

MAZZARINO, J. VIER A. Conhecer não é representar - Reflexões sobre representação na educação ambiental. Perspectiva, Florianópolis, v. 31, n. 3, p.1005-1020, set./dez. 2013.

MENDONÇA, R. A experiência na natureza segundo Joseph Cornell: A educação pelas pedrasecoturismo e educação ambiental. Célia Serrano (Org.) São Paulo: Chronos, 2000, p.135-154.

MENDONÇA, R. Educação Ambiental Vivencial. In: Encontros e caminhos: formação de educadoras(es) ambientais e coletivos educadores, Vol. 2, 2007. p. 119-129.

MINISTÉRIO DA EDUCAÇÃO. Tratado De Educação Ambiental Para Sociedades Sustentáveis E Responsabilidade Global. Brasília: MEC, 1992. Disponível em: <http://portal.mec.gov.br/secad/arquivos/pdf/educacaoambiental/tratado.pdf>. Acesso em: 29 jan. 2014.

PERALTA, C.H.G. Experimentos educacionais: eventos heurísticos transdisciplinares em educação ambiental. In: RUSCHEINSKY, A. (Org.). Educação ambiental: abordagens múltiplas. Porto Alegre: Artmed, 2002, p.105-125.

SILVEIRA, E. A arte do encontro: a educação estética ambiental atuando com o teatro do oprimido. Educação em Revista, Belo Horizonte, v.25, n.3, p.369-394, Dez. 2009. Disponível em: <http://www.scielo.br/pdf/edur/v25n3/18.pdf〉. Acesso em: 13 jan. 2014.

Versão recebida em: 15/04/2014

Aceite em: 14/10/2015 